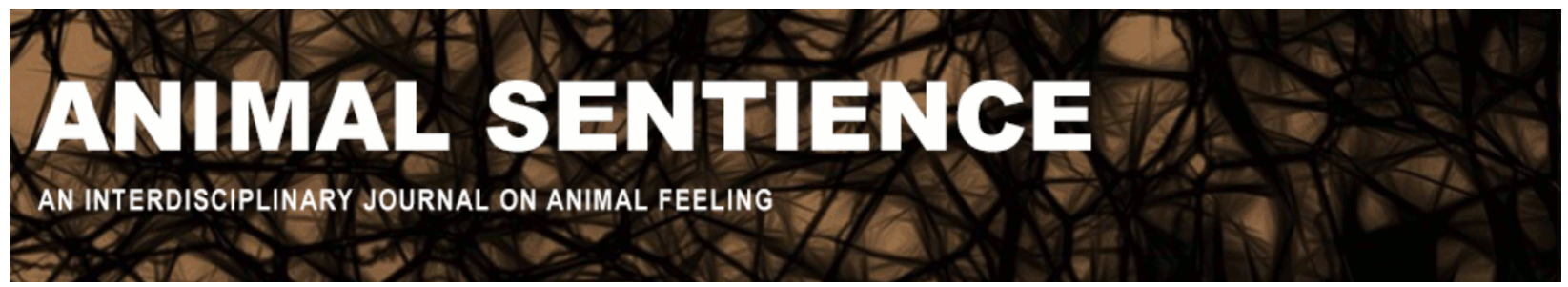

Schuck-Paim, Cynthia (2020) Intensive animal farming conditions are a major threat to global health. Animal Sentience 30(8)

DOI: $10.51291 / 2377-7478.1635$

Date of submission: $2020-08-28$

Date of acceptance: $2020-08-28$

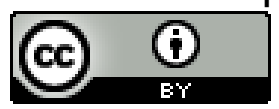

This article has appeared in the journal Animal

Sentience, a peer-reviewed journal on animal

cognition and feeling. It has been made open access,

free for all, by WellBeing International and deposited

in the WBI Studies Repository. For more information,

please contact

wbisr-info@wellbeingintl.org.

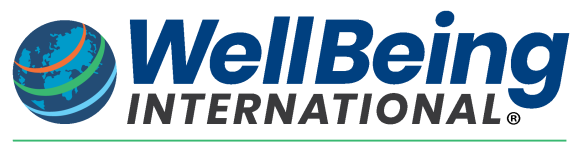

SOLUTIONS FOR PEOPLE, ANIMALS AND ENVIRONMENT 


\title{
Intensive animal farming conditions are a major threat to global health
}

\author{
Commentary on Wiebers \& Feigin on Covid Crisis
}

\section{Cynthia Schuck-Paim}

\begin{abstract}
Wiebers \& Feigin accurately propose that reducing the risks posed by infectious disease outbreaks and other global health challenges will depend critically on transitioning away from intensive animal farming practices. Creating the right incentive structure for this transition to happen is one of the great challenges in the years to come, but a much needed step to ensure the health and well-being of current and future generations.
\end{abstract}

Cynthia Schuck-Paim is a zoologist and researcher on the epidemiology of human and animal diseases. Her published research includes multiple studies on the mortality impact of influenza pandemics and the burden of respiratory infectious diseases. Website

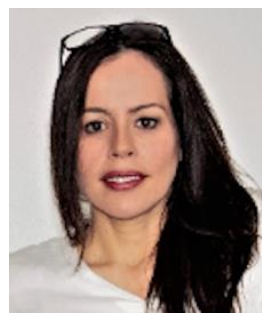

Wiebers \& Feigin's (2020a,b) (W\&F) target article is commendable for addressing the causal role of the large-scale confinement of animals in industrial farming operations in the emergence of zoonotic diseases and antibiotic resistance. Over the last century, pandemics, epidemics and outbreaks of infectious diseases with pandemic potential have had their origins predominantly in the contamination of humans with pathogens from wild animals or in pathogens "cultured" in immunosuppressed animals raised in intensive systems. While COVID-19 has shone a bright light onto the public health risks associated with the capture, production and trade of wild species, there is an even greater threat posed by intensive animal farming, which accounts for most of the meat produced globally.

Livestock species now constitute more biomass than all wild mammals combined, harboring a much larger number of zoonotic viruses than their wild relatives (Johnson et al. 2020). Importantly, as discussed by W\&F, the ideal conditions for the emergence of highly pathogenic viruses are present in intensive farming systems, enabling the rapid transmission of infections and the reassortment of genetic material from different viral strains. Pigs, in particular, having receptors for avian, swine, and human influenza viruses, are regarded as ideal mixing vessels to generate influenza viruses with pandemic potential (Ma et al 2008), as illustrated not so long ago by the 2009/H1N1pdm pandemic. Similarly, intensive poultry farming has made highly pathogenic avian influenza (HPAl) pervasive, with most reassortments and conversion events from low pathogenic to highly pathogenic strains reported in commercial poultry farms in high-income countries (where intensive farming is ubiquitous) and in countries transitioning to intensive production (Dhingra et al 2018). In just the last three weeks, from Aug 01 to Aug 20, 2020, new outbreaks of HPAI were reported in Australia, Taiwan, Vietnam and Russia, with previously reported outbreaks ongoing in South Africa, Nigeria, Afghanistan, China, India, Korea, Philippines and Bulgaria (OIE 2020). These many new cases provide numerous opportunities for these viruses to mutate or reassort with other strains and at some point acquire the capability of sustained human transmission.

Industry representatives often argue that zoonotic disease risk is greatly reduced by the use of strict biosecurity measures. Although protocols and sanitary standards to prevent and 
control infectious diseases do exist, the sheer scale of the outputs of industrial farming operations, the pulverization of activities to independent producers in vertically integrated systems, the transport of live animals nationally and across borders, and the many possibilities of contamination during slaughter and processing make it unlikely that these measures would be sufficient even if they were strictly implemented (Schuck-Paim and Alonso 2020) -- which they are not, because poor compliance with biosecurity is endemic in the industry (Scott et al. 2018). The borderless nature of zoonotic diseases means that a biosecurity risk in one place is a biosecurity risk everywhere.

As we seek to reduce the risks of future pandemics after COVID-19, we will need to promote the regulatory and market incentives needed to transition away from industrial animal farming systems and towards the development of globally safer food sources. Divestment from companies that participate in factory farming operations will be critical. For example, recently, the Farm Animal Investment Risk \& Return initiative, a coalition of investors currently representing over US\$20 trillion in assets, created a pandemic ranking that combines various factors relevant to risk of pandemics, to help investors fare companies in terms of the level of pandemic risk they represent (FAIRR 2020). Similarly, investment towards the advancement of technologies for the development of safer food sources able to compete in terms of taste, convenience and price with traditional animal-sourced foods will also be crucial (Anomaly 2020).

The impact of environmental policies on global health issues will also need to be more clearly established. While a transition towards environmentally efficient resources (which use less land, water and pollute less) is very much needed, it is not uncommon to find proposals for increased sustainability in the livestock sector that directly advocate for the intensification of animal farming, or that promote it as an unintended by-product. For example, by increasing the price of beef relative to other meats, interventions such as taxing systems based on the carbon footprint of products may translate into a large-scale switch to the consumption of poultry and pork, which are overwhelmingly raised in intensive farming operations.

Although the livestock industry is often praised for its value as a propeller of economies, a more comprehensive analysis shows that many of the claimed benefits are intrinsically linked to market distortions in the form of subsidies, credits, and negative externalities, including loss of natural capital (Schuck-Paim \& Winckler 2019), animal suffering at unprecedented levels and the enormous health and financial burden of infectious diseases. Intensive animal farming systems represent an unacceptable level of threat to public health and to economies everywhere. As we are witnessing with COVID-19, promoting and facilitating a transition towards the development of modern and safer methods of food production, as proposed by W\&F, is at the core of protecting the well-being of current and future generations.

\section{References}

Anomaly, J. (2020) Cultured meat would prevent the next Covid crisis. Animal Sentience $30(5)$

Dhingra, M.S., Artois, J, Dellicour, S., Lemey, P., Dauphin, G., von Dobschuetz, S., van Boeckel, T.P., Castellan, D.M., Morzaria, S., Gilbert, M. (2018). Geographical and 
historical patterns in the emergence of novel highly pathogenic avian influenza (HPAI) $\mathrm{H} 5$ and $\mathrm{H} 7$ viruses in poultry. Frontiers in Veterinary Science 5: 84.

FAIRR (2020). An industry infected. FAIRR. Accessed August 24, 2020.

Johnson, C.K., Hitchens, P.L., Pandit, P.S., Rushmore, J. Evans, T.S., Young, C.C.W., Doyle, M.M.. 2020. Global shifts in mammalian population trends reveal key predictors of virus spillover risk. Proceedings of the Royal Society B: Biological Sciences 287 (1924): 20192736.

Ma, W., Kahn, R.E., Richt, J.A. (2008). The pig as a mixing vessel for influenza viruses: human and veterinary implications. Journal of Molecular and Genetic Medicine: An International Journal of Biomedical Research 3 (1): 158-66.

OIE (2020). Highly pathogenic avian influenza (HPAI). World Animal Health Information and Analysis Department, Report No.13, August.

Schuck-Paim, C., Alonso, W.J. (2020). Pandemics, Global Health and Consumer Choices. Cria Editora, Sao Paulo.

Schuck-Paim, C., Winckler, M. (2019). Food animals in Brazil: five decades of transformation. In: Naconecy C. (eds) Animals in Brazil. The Palgrave Macmillan Animal Ethics Series. Palgrave Pivot, Cham.

Scott, A.B., Singh, M. Groves, P. Hernandez-Jover, M., Barnes, B., Glass, K., Moloney, B., Black, A., Toribio, J. (2018). Biosecurity practices on Australian commercial layer and meat chicken farms: performance and perceptions of farmers. PloS One 13 (4): e0195582.

Wiebers, D.O., Feigin. V.L. (2020a). What the COVID-19 crisis is telling humanity. Neuroepidemiology 363 (4).

Wiebers, D.O., Feigin. V.L. (2020b). What the COVID-19 crisis is telling humanity. Animal Sentience 30 (1). 